\title{
The Response of Grain Legumes to Vermicompost at Germination and Seedling Stages
}

\begin{abstract}
Background: The importance of organic fertilizers in agricultural production has increased due to the negative effects of intensive chemical fertilizer use on soil, the environment and human health. Vermicompost, as a rich organic fertilizer and soil amendment material, maybe a viable alternative to chemical fertilizers. While a low concentration of vermicompost has a promotive effect on growth, it may lead to inhibition of germination and seedling growth. Therefore, this study aimed to find appropriate dose ranges for vermicompost application.

Methods: The study was carried out as a factorial experiment with a completely randomized design with three replications. The experiment was conducted in a growth chamber as a pot study with four doses of vermicompost (control, 10, 20 and $30 \%$ ). Eight cultivars from four different species were used. The response of germination and seedling traits to increased vermicompost concentration was investigated.

Result: In general, while $10 \%$ and $20 \%$ of vermicompost showed a promotive effect depending on species, higher dose inhibited the germination and dry matter accumulation. As a result, the promotive effect of low dose and inhibitory effect of higher doses are thought to be caused by the complex chemical composition of vermicompost and increasing medium $\mathrm{pH}$. Therefore, the concentration of the vermicompost that will cause $\mathrm{pH}$ changes should be carefully considered and the $\mathrm{pH}$ range in which the plant species show optimum growth should be well determined.
\end{abstract}

Key words: Dry matter accumulation, Germination, Humic substances, Organic manure, Pulses, Vermicast.

\section{INTRODUCTION}

Plant growth is affected by many internal and external factors from germination to maturity. One of the most important stages is germination since it is sensitive to physical and chemical factors of the rhizosphere and it directly affects seedling growth. Seed germination is a complex physiological and biochemical process that starts with the imbibition of water for metabolism activation and finishes with the radicle elongation (Ayuso et al., 2019). Seeds from different species prefer various environmental factors for optimum germination. Seed germination is affected by biotic and abiotic factors such as water, temperature, oxygen, light, $\mathrm{pH}$, microorganisms, minerals and hormones (Miransari and Smith, 2014; Han and Yang, 2015). Due to its high enzyme activity and rich chemical and microbial composition, vermicompost is an important material for improved germination initiation and seedling growth (Sutaria et al., 2010).

Vermicompost is commonly produced by earthworm species such as Eisenia fetida, Eisenia andrei and Lumbricus rubellus. The most preferred earthworm species are Eisenia fetida and Lumbricus rubellus due to their high adaptability (Şahin and Ceritoglu, 2020). Organic residues transformed into vermicompost can be used as an effective fertilizer and soil amendment material. In addition to rich nutrient composition and hormones, vermicompost has vitamins, enzymes, humic substances and microbial activity (Blouin et al., 2019; Gupta et al., 2020).

Several studies report conflicting effects of vermicompost on germination. While some researchers
${ }^{1}$ Department of Field Crops, Faculty of Agriculture, Siirt University, Siirt, Turkey.

${ }^{2}$ Department of Animal Science, Faculty of Agriculture, Siirt University, Siirt, Turkey.

${ }^{3}$ Department of Agricultural Biotechnology, Faculty of Agriculture, Siirt University, Siirt, Turkey.

Corresponding Author: M. Ceritoglu, Department of Field Crops, Faculty of Agriculture, Siirt University, Siirt, Turkey.

Email: ceritoglu@siirt.edu.tr

How to cite this article: Ceritoglu, M., Erman, M., Ceritoglu, F. and Bektas, H. (2021). The Response of Grain Legumes to Vermicompost at Germination and Seedling Stages. Legume Research. 44(8): 936-941. DOI: 10.18805/LR-610.

Submitted: 08-01-2021 Accepted: 29-03-2021 Online: 29-04-2021

reported promotive effects of vermicompost on germination, growth and yield (Sharma et al. 2018), others reported toxic effects (Rupani et al., 2018). So, the knowledge of the effects of vermicompost on germination and seedling growth is still limited and inconclusive. Therefore, the aims of this study were; 1) to understand the effect of vermicompost in grain legume germination and seedling development and 2) to determine optimum vermicompost doses on these species.

\section{MATERIALS AND METHODS}

\section{Materials and experimental design}

The study was carried out in an $8 \times 4$ factorial design with a 
The Response of Grain Legumes to Vermicompost at Germination and Seedling Stages

completely randomized design with three replications. The pot study was conducted in a growth chamber in Siirt University, Turkey in 2019. Cultivars Firat-87 (LF) and Kafkas (LK) from Lentil (Lens culinaris L.), Arda (CA) and Diyar-95 (CD) from chickpea (Cicer arietinum L.), Altınay (GA) and Cinsoy (GC) from soybean (Glycine max L.) and Green pearl (PIG) and Sprinter (PIS) from pea (Pisum sativum L.) were used in the experiment. The seeds were provided by the GAP International Agricultural Research and Training Center (GAPUTAEM), Aegean Agricultural Research Institute (AARI) and commercial seed companies. All cultivars are commonly cultivated in Turkey and selected based on previous agronomic and genotypic diversity (Ceritoglu et al., 2020). Vermicompost produced by cow manure was provided from a traditional company (Ekosol Tarım ve Hayvancılık A.Ş.).

Four doses of vermicompost were applied as follows: control ( $100 \%$ soil mixture), $10 \%$ vermicompost (VC) $+90 \%$ soil mixture (V1), $20 \% \mathrm{VC}+80 \%$ soil mixture (V2) and $30 \%$ $\mathrm{VC}+70 \%$ soil mixture (V3). The soil mixture was constituted a homogeneous mixture of peat: sand: soil $(2: 1: 1)$. The soil taken from the A-horizon of arable land of Siirt University was of clay-loam texture. Basic physio-chemical characteristics of soil and vermicompost are presented in Table 1.

The pots were filled with $1.2 \mathrm{~kg}$ air-dried soil mixture. Pots were excessively irrigated up to field capacity. When the gravimetric water draining was complete, the pots were weighted. The weight of the pot with dried soil mixture was recorded to determine the content of water at $100 \%$ field capacity and it was calculated for all treatments (Amiri et al., 2017). The seeds were surface sterilized with $70 \%$ ethyl alcohol (1 $\mathrm{min}$ ) and $5 \%$ sodium hypochlorite (10 mins) and then washed three times with distilled water. After sterilization, the seeds were exposed to hydro-priming (seed priming with distilled water) for 16 hours to ensure homogeneous germination and transplanted as four seeds per pot. Temperature and relative humidity were ranged between $25-27^{\circ} \mathrm{C}$ and $60-70 \%$, with a light/dark period of $14: 10 \mathrm{~h}$. The pots were equally irrigated following requirements. Germination characteristics of seedlings were recorded for ten days at 24-hour intervals. The plants were grown for 60 days to investigate root and shoot growth.

\section{Germination characteristics and seedling growth measurements}

The germination characteristic of cultivars from four different species was investigated under controlled conditions. The appearance of cotyledon leaves above the soil surface was considered as germination criteria. Germination percentage (GP), mean germination time (MGT), germination index (GI), coefficient of uniformity of germination (CUG), root dry weight (RDW) and shoot dry weight (SDW) were investigated in the study. Normal germinated seeds were counted and the GP was calculated as an indicator of the viability of the seeds by ISTA (2011). The MGT was calculated according to Matthews and Hosseini (2006). The GI was determined with the equation used by Kader (2015). The CUG was calculated by the method of Ellis and Roberts (1981). After harvesting, roots and shoots were separated and dried for 3 days at $80^{\circ} \mathrm{C}$ and weighted with a precision scale.

\section{Statistical analysis}

The normality test of Shapiro and Wilks (1965) was applied to data. The results were subjected to analysis of variance using $R$ v.3.5.2. according to completely randomized design and mean values were grouped by TUKEYs Multivariate test (R Core Team, 2020).

Table 1: Basic physio-chemical properties of soil and vermicompost.

\begin{tabular}{lcccccccc}
\hline & $\mathrm{pH}$ & $\begin{array}{c}\mathrm{EC} \\
(\mathrm{Ds} \mathrm{m})\end{array}$ & $\begin{array}{c}\mathrm{CaCO}_{3} \\
(\%)\end{array}$ & $\begin{array}{c}\text { Organic matter } \\
(\%)\end{array}$ & $\begin{array}{c}\mathrm{P}_{2} \mathrm{O}_{5} \\
(\mathrm{Kg} \mathrm{da})\end{array}$ & $\begin{array}{c}\mathrm{K}_{2} \mathrm{O} \\
(\mathrm{Kg} \mathrm{da})\end{array}$ & $\begin{array}{c}\text { Total humic and } \\
\text { fulvic acid }(\%)\end{array}$ \\
\hline $\mathrm{S}$ & 7.65 & 6.69 & 9.1 & 1.1 & 1.72 & 153 & - \\
$\mathrm{VC}$ & $6.8-8.5$ & 5.0 & - & 35 & $1-2$ & $1.5-2.5$ & 14 & 20 \\
\hline
\end{tabular}

(S: Soil, VC: Vermicompost, EC: Electrical conductivity).

Table 2: Analysis of variance on germination characteristics and seedling traits.

\begin{tabular}{|c|c|c|c|c|c|c|c|}
\hline \multirow{2}{*}{ Source of variation } & \multicolumn{3}{|c|}{ GP } & \multicolumn{2}{|c|}{ MGT } & \multicolumn{2}{|c|}{$\mathrm{GI}$} \\
\hline & DF & MS & F prob. & MS & F prob. & MS & $\mathrm{F}$ prob. \\
\hline Cultivars (C) & 7 & 1271.4 & * & 4.32 & ** & 210.9 & ** \\
\hline Vermicompost (VC) & 3 & 857.2 & ns & 2.93 & ** & 62.4 & ns \\
\hline \multirow[t]{3}{*}{$C_{x}$ VC (interaction) } & 21 & 286.8 & ns & 0.57 & * & 21.4 & * \\
\hline & & \multicolumn{2}{|c|}{ CUG } & \multicolumn{2}{|c|}{ RDW } & \multicolumn{2}{|c|}{ SDW } \\
\hline & DF & MS & F prob. & MS & F prob. & MS & F prob. \\
\hline Cultivars (C) & 7 & 74.5 & ** & 0.0138 & ** & 1.358 & $* *$ \\
\hline Vermicompost (VC) & 3 & 42.1 & ** & 0.0059 & * & 0.166 & ** \\
\hline $\mathrm{C}_{\mathrm{x}} \mathrm{VC}$ (interaction) & 21 & 4.9 & ** & 0.0021 & * & 0.095 & ** \\
\hline
\end{tabular}

$\left({ }^{*}: p<0.05,{ }^{* *}: p<0.01, n s:\right.$ no significant difference, GP: Germination percentage, MGT: Mean germination time, Gl: Germination index, CUG: Coefficient of uniformity of germination, RDW: Root dry weight, SDW: Shoot dry weight). 
The Response of Grain Legumes to Vermicompost at Germination and Seedling Stages

\section{RESULTS AND DISCUSSION}

According to results, cultivars, vermicompost doses and their interactions significantly affected all parameters except the GP. The cultivars showed statistically significant differences for all traits $(<0.05$ in the GP and $<0.01$ for the others). Cultivars and vermicompost doses showed significant differences at the MGT, RDW and SDW. Increasing vermicompost doses are almost negatively affected all investigated traits (Table 2).

Three different groups related to germination characteristics were obtained for the response of cultivars to vermicompost. The GP was not affected by vermicompost doses. While 10 and $20 \%$ concentration of vermicompost had a promotive effect, $30 \%$ caused inhibition in the firstgroup (chickpea cvs.). Pea cultivars were hardly ever affected by vermicompost except for the SDW and were in the second group. The last group (lentil and soybean cvs.) was the most sensitive to the inhibitory effect of higher concentrations. However, the $3^{\text {rd }}$ group was positively affected from 10 and $20 \%$ concentrations. Morphological alteration of shoot biomass due to vermicompost was higher than root biomass (Table 3 ).

The genotypic effect was significant for all parameters. The highest GP (93.8\%) was observed in the LK from the lentil, while the lowest one $(60.4 \%)$ was determined in the CA from chickpea. All cultivars were germinated within 3 to 6 days except for the GA and GC from soybean. The earliest germinating species was lentil, while the latest one was soybean. The diagram of the MGT is an indicator of the sensitivity of soybean and lentil cultivars to increasing vermicompost doses. While $10 \%$ vermicompost application led to improved Gl except for the LK, higher doses caused a linear decrease. All cultivars were negatively affected by all doses of vermicompost in terms of the CUG, except for the $C A$ and $C D$. The seedling traits exhibited similar responses with germination characteristics. Lower doses of vermicompost caused promotive effects for all cultivars, however, higher concentrations always inhibited growth. Soybean and pea cultivars exhibited a higher growth rate compared to other legumes (Fig 1).

Table 3: Effect of vermicompost doses on germination characteristics and seedling traits.

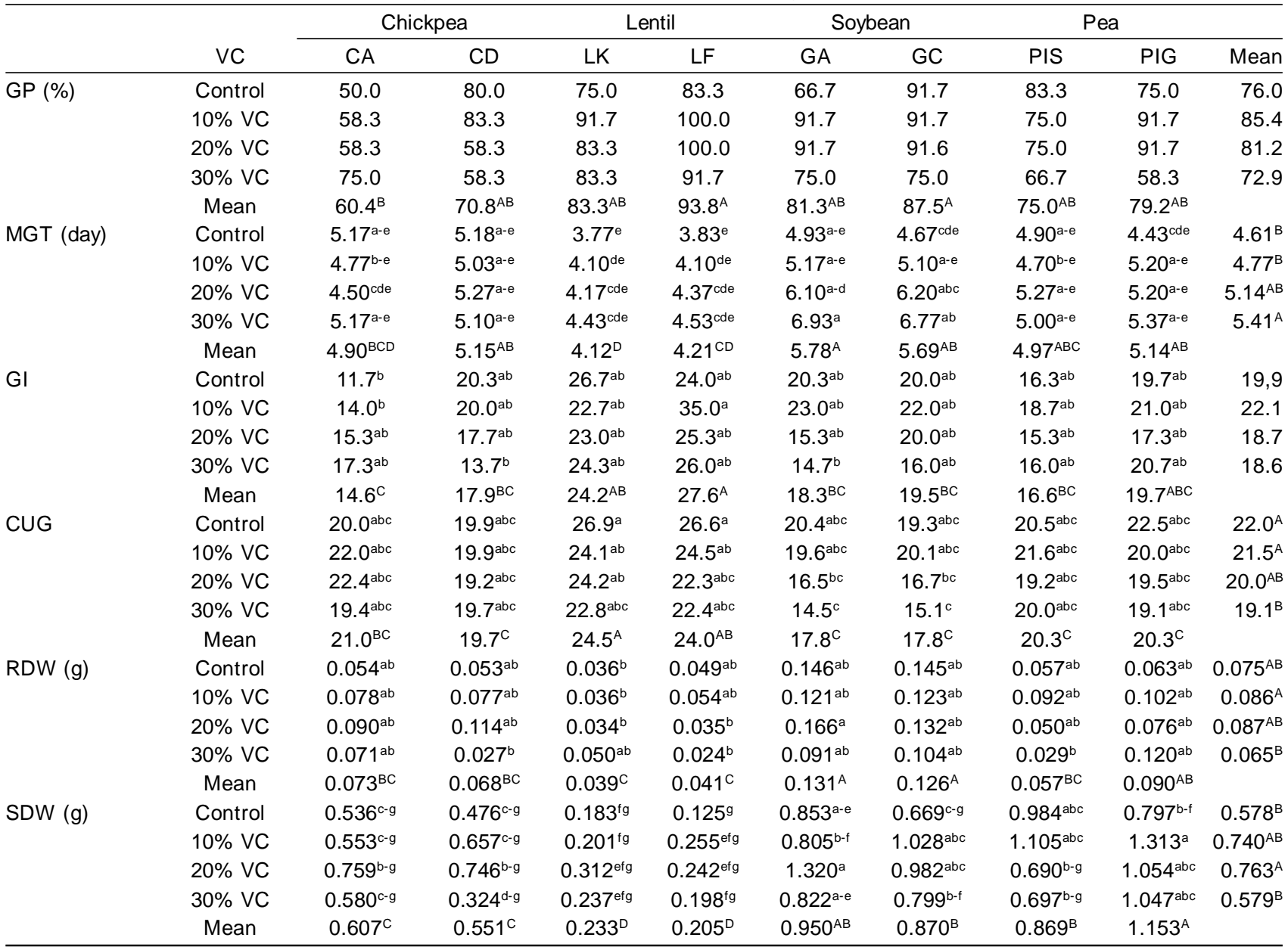

(VC: Vermicompost, GP: Germination percentage, MGT: Mean germination time, Gl: Germination index, CUG: Coefficient of uniformity of germination, RDW: Root dry weight, SDW: Shoot dry weight, CA: Arda, CD: Diyar-95, LK: Kafkas, LF: Fırat-87, GA: Altınay, GC: Cinsoy, PIS: Sprinter, PIG: Green pearl). 
The Response of Grain Legumes to Vermicompost at Germination and Seedling Stages

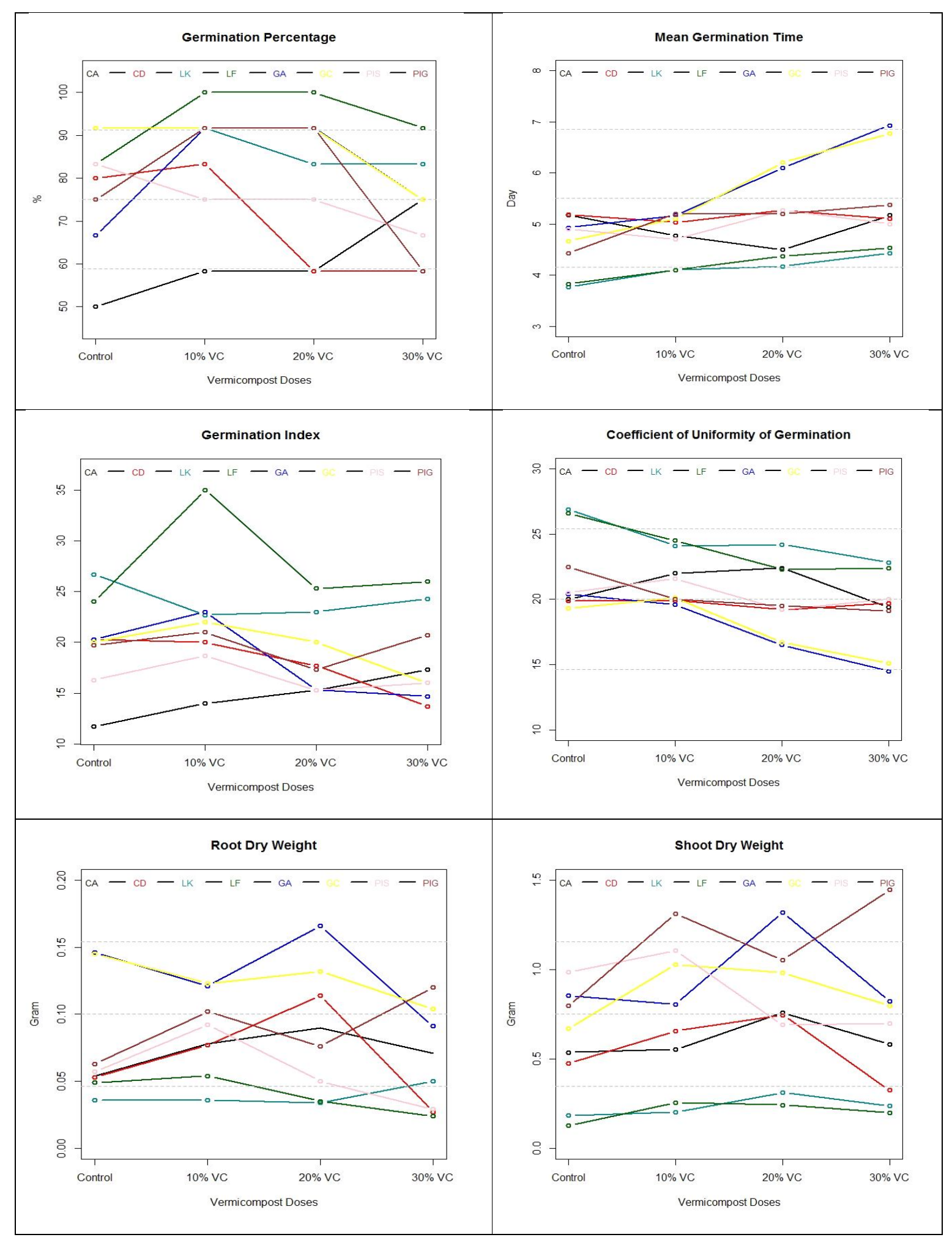

Fig 1: Responses of cultivars to vermicompost doses.

(CA: Arda, CD: Diyar-95, LK: Kafkas, LF: Firat-87, GA: Altınay, GC: Cinsoy, PIS: Sprinter, PIG: Green pearl). 
The experiment was aimed to evaluate the effect of vermicompost on germination and seedling development of grain legumes under controlled conditions. The $10 \%$ and $20 \%$ concentrations of vermicompost promoted all traits in used cultivars, however, each cultivar exhibited different responses to increasing doses. In general, $20 \%$ concentration seems as the highest beneficial threshold and above caused inhibition of seed germination and seedling growth. The effect of vermicompost application may reveal different results due to interactions with various factors such as ecological factors or microbial interaction under field conditions. Thus, the study was carried out under controlled conditions to eliminate environmental fluctuations.

While low concentrations of vermicompost (10-20\%) were effective on germination and growth as reported in previous reports, it has been also stated that higher doses do not promote and nor inhibit all traits (Ceritoglu and Erman, 2020). Although GP significantly changed depending on species and cultivars, vermicompost doses did not have any stimulating or inhibitory effect on it in the present study. Germination vigor is affected by water uptake, seed viability, environmental factors, genetic characteristics and phytohormones (Miransari and Smith, 2014). Germination percentage was not inhibited by the vermicompost application, even at the highest dose (30\%). levinsh et al. (2011) report that increasing the concentration of vermicompost (especially higher than $30 \%$ ) leads to linear decreases in the GP. Similarly, the inhibitory effect of higher vermicompost doses can be observed in other traits (Table 3).

The MGT delayed with even $10 \%$ vermicompost application in five cultivars. Tolerance to elevated $\mathrm{pH}$ was the highest in chickpea. Vermicompost which has an alkaline character led to increasing electrical conductivity and $\mathrm{pH}$ in the soil (Hanc and Vasak, 2015). Pervin et al. (2013) stated that $\mathrm{pH}$ has a vital role in urease activity, which is an important enzyme for the germination process and the structure of urease isolated from chickpea is alkaline. Mohebbi and Mahler (1989) determined that lentil exhibits optimum growth in close to neutral $\mathrm{pH}$ and high acidity or alkalinity strongly inhibits growth. Zou and Hou (2017) determined that the protease enzyme has a vital role in protein metabolism during germination and the highest activity of it was observed in $\mathrm{pH} 5$. So, high medium $\mathrm{pH}$ inhibited the germination and growth traits in soybean. Similarly, pea cultivars were negatively affected by increasing vermicompost doses possibly due to increasing $\mathrm{pH}$ value. Beal and Metha (1985) suggest $\mathrm{pH}$ values 5.0 to 5.2 for optimum growth and metabolic activity in pea.

The GI enables an easy comparison of tested seeds. So, especially $10 \%$ vermicompost application led to stimulating germination speed and index. In general, the Gl exhibited a positive relationship with MGT in the study. The CUG focuses on fluctuations and stability of germination between the first and last germinated seeds. The uniform stand establishment has a vital role for crops. Nonhomogenous emergence decreases plant growth, yield and quality due to variation in phenological duration (Stivers, 2017). While the GI was not affected by vermicompost, the CUG showed significant differences depending on increasing doses (Table 2). Humic substances, phytohormones, or some microbial metabolites that are water-soluble bioactive substances in vermicompost promote the germination process (Arancon et al. 2007; Ceritoglu et al. 2018). However, increasing concentrations of bioactive components may cause inhibition on germination and this interaction may vary by genotype. In general, increasing vermicompost doses reduced the uniformity of germination. It is thought that genotypic responses exhibit different characters towards vermicompost solution (intake heterogeneity), therefore, it caused heterogeneous stand establishment.

While 10 and $20 \%$ concentrations of vermicompost had a stimulative effect on the shoot and root growth except for the LF and pea cultivars, 30\% concentration inhibited all cultivars (Table 4). The main reason for this situation is thought to be caused by the slow-solubilizing and complex character of vermicompost which contains some plant growth-promoting phytohormones (such as auxin and gibberellins), macro and micronutrients. Ceritoglu and Erman (2020) stated that even though a low dose of vermicompost increases plant growth, seed yield and yield components in the LF, higher doses inhibited it. Pant et al. (2012) stated that a low quantity of gibberellin (198 $\mathrm{ng} \mathrm{L}^{-1}$ ) in vermicompost tea stimulates seed germination and root growth. levinsh (2011) determined that vermicompost applications have a substantial effect on leaf chlorophyll content and photosynthetic pigments. Vermicompost is reported to promote root growth due to the auxin impact of humic substances (Trevisan et al. (2010). Similarly, Canellas et al. (2002) determined that humic substances can improve root growth and promote $\mathrm{H}^{+}$-ATPase enzyme activity in maize.

\section{CONCLUSION}

Although optimum doses of vermicompost had a stimulative effect on the germination and seedling growth, it has been determined that the appropriate dose for the species and varieties changes significantly. It has an inhibitory effect on germination and seedling growth if the threshold value is exceeded. The $20 \%$ vermicompost application led to the improved growth in chickpea while $10 \%$ was enough to observe a significant effect on other species. Although $20 \%$ concentration of vermicompost stimulated root and shoot growth compared to control, differences between 10, 20 and $30 \%$ were small, thereby, using $10 \%$ concentration of vermicompost seems. Inhibition is thought to be caused by the density of humic substances and elevated soil $\mathrm{pH}$. So, vermicompost dose should be determined carefully to benefit from its stimulating effects. 
The Response of Grain Legumes to Vermicompost at Germination and Seedling Stages

\section{REFERENCES}

Amiri, H., Ismaili, A. and Hosseinzadeh, S.R. (2017). Influence of vermicompost fertilizer and water deficit stress on morphophysiological features of chickpea (Cicer arietinum L. cv. Karaj). Compost Science and Utilization. 25: 152-165.

Arancon, N.Q., Edwards, C.A., Dick, R. and Dick, L. (2007). Vermicompost tea production and plant growth impacts. Biocycle. 48: 51-52.

Ayuso, M., Landin, M., Gallego, P.P. and Esther, M. (2019). Artificial intelligence tools to better understand seed dormancy and germination. In: Seed Dormancy and Germination. $1^{\text {st }}$ Edn, London, combine.

Beal, L. and Metha, T. (1985). Zinc and phytate distribution in peas. Influence of heat treatment, germination, $\mathrm{pH}$, substrate and phosphorus on pea phytate and phytase. Journal of Food Science. 50: 96-100.

Blouin, M., Barrere, J., Meyer, N., Lartigue, S., Barot, S. and Mathieu, J. (2019). Vermicompost significantly affects plant growth: A meta-analysis. Agronomy for Sustainable Development. 39: 34.

Canellas, L.P., Olivares, F.L., Okorokova-Façanha, A.L. and Façanha, A.R. (2002). Humic acids isolated from earthworm compost enhance root elongation, lateral root emergence and plasma membrane $\mathrm{H}^{+}$-ATPase activity in maize roots. Plant Physiology. 130: 1951-1957.

Ceritoglu, M., Şahin, S. and Erman, M. (2018). Effects of vermicompost on plant growth and soil structure. Selcuk Journal of Agriculture and Food Science. 32(3): 607-615.

Ceritoglu, M. and Erman, M. (2020). Effect of vermicompost application at different sowing dates on some phenological, agronomic and yield traits in lentil. Journal of International Environmental Application and Science. 15(3): 158-166.

Ceritoglu, M., Ceritoglu, F., Erman, M. and Bektas, H. (2020). Root system variation of pulse crops at early vegetative stage. Notulae Botanicae Horti Agrobotanici Cluj-Napoca. 48(4): 2182-2197.

Ellis, R.A. and Roberts, E.H. (1981). The quantification of aging and survival in orthodox seeds. Seed Science and Technology. 9: 373-409.

Gupta, S.C., Trivedia, B.K. and Singh, P. (2020). Effect of diverse nutrient application on symbiotic traits, yield attributes, nutrient uptake, microbial population, dehydrogenase activity and productivity of chickpea (Cicer arietinum L.) in black soils. Legume Research. 43(6): 844-849.

Han, C. and Yang, P. (2015). Studies on the molecular mechanisms of seed germination. Proteomics. 15: 1671-1679.

Hanc, A. and Vasak, F. (2015). Processing separated digestate by vermicomposting technology using earthworms of the genus Eisenia. International Journal of Environmental Science and Technology. 12: 1183-1190.

levinsh, G. (2011). Vermicompost treatment differentially affects seed germination, seedling growth and physiological status of vegetable crop species. Plant Growth Regulation. 65: 169-181.

ISTA. (2011). International Rules for Seed Testing. Bassersdorf, Switzerland.

Kader, M.A. (2015). A comparison of seed germination calculation formulae and the associated interpretation of resulting data. Journal and Proceedings of the Royal Society of New South Wales. 138: 65-75.
Mohebbi, S. and Mahler, R.L. (1989). The effect of soil pH on wheat and lentils grown on an agriculturally acidified northern Idaho soil under greenhouse conditions. Communications in Soil Science and Plant Analysis. 20(3-4): 359-381.

Matthews, S. and Hosseini, M.K. (2006). Mean germination time as an indicator of emergence performance in soil of seed lots of maize (Zea mays). Seed Science and Technology. 34: 339-347.

Miransari, M. and Smith, D.L. (2014). Plant hormones and seed germination. Environmental and Experimental Botany. 99: 110-121.

Pant, A., Radovich, T.J.K., Hue, N.V. and, Paull, R. (2012). Biochemical properties of compost tea associated with compost quality and effects on pak choi growth. American Society of Horticultural Science Annual Conference. 3 Aug-31 July, Miami.

Pervin, M.S., Jahan, M.G.S., Rana, A.Y.K., Sana, N.K., Rahman, M.H. and Shaha, R.K. (2013). Effects of environmental variables on urease in germinating chickpea (Cicer arietinum L.) seed. Journal of Stress Physiology and Biochemistry. 9(3): 345-356.

R Core Team. (2020). R: A language and environment for statistical computing. R Foundation for Statistical Computing, March 18, Vienna, Austria. https://www.r-project.org/index.html

Rupani, P.F., Embrandiri, A., İbrahim, M.H., Ghole, V. and Lee, C.T. (2018). Effects of different vermicompost extracts of palm oil mill effluent and palm-pressed fiber mixture on seed germination of mung bean and its relative toxicity. Environmental Science and Pollution Research. 25(36): 35805-35810.

Shapiro, S.S. and Wilk, M.B. (1965). An analysis of variance test for normality (complete samples). Biometrika. 52(34): 591-611.

Sharma, A., Sharma, R.P., Katoch, V. and Sharma, G.D. (2018). Influence of vermicompost and split applied nitrogen on growth, yield, nutrient uptake and soil fertility in pole type french bean (Phaseolus vulgaris L.) in an acid alfisol. Legume Research. 41(1): 126-131.

Stivers, L. (2017). Understanding Seeds and Seedling Biology. PennState Extention, March 9, Pennsylvania. https:// extension.psu.edu/understanding-seeds-and-seedlingbiology.

Sutaria, G.S., Akbari, K.N., Vora, V.D., Hirpara, D.S. and Padmani, D.R. (2010). Response of legume crops to enriched compost and vermicompost on vertic ustochrept under rain fed agriculture. Legume Research. 33(2): 128-130.

Şahin, S. and Ceritoglu, M. (2020). A critical step towards vermicompost production: Choosing appropriate earthworm species. In: Theory and Research in Agriculture, Forestry and Aquaculture Sciences, $1^{\text {st }}$ Edn, Gece Publishing, Ankara.

Trevisan, S., Pizzeghelloi, S., Ruperti, B., Fransisco, O., Sassi, A., Palme, K., Quaggiotti, S. and Nardi, S. (2010). Humic substances induce lateral root formation and expression of the early auxin-responsive IAA19 gene and DR5 synthetic element of Arabidopsis. Plant Biology. 12: 604-614.

Zou, Y. and Hou, X. (2017). Effects of germination conditions on peptides accumulation in soybean [Glycine max (L.) Merr.]. Acta Alimentaria. 46(3): 346-354. 